\title{
In vitro evaluation of skin adhesives during perspiration
}

Eiler, Johannes; Hansen, Daniel; Bingöl, Bahar; Hansen, Kristoffer; Heikenfeld, Jason; Thormann, Esben

Published in:

International Journal of Adhesion and Adhesives

Link to article, DOI:

10.1016/j.ijadhadh.2020.102574

Publication date:

2020

Document Version

Peer reviewed version

Link back to DTU Orbit

Citation (APA):

Eiler, J., Hansen, D., Bingöl, B., Hansen, K., Heikenfeld, J., \& Thormann, E. (2020). In vitro evaluation of skin adhesives during perspiration. International Journal of Adhesion and Adhesives, 99, [102574]. https://doi.org/10.1016/j.ijadhadh.2020.102574

\section{General rights}

Copyright and moral rights for the publications made accessible in the public portal are retained by the authors and/or other copyright owners and it is a condition of accessing publications that users recognise and abide by the legal requirements associated with these rights.

- Users may download and print one copy of any publication from the public portal for the purpose of private study or research.

- You may not further distribute the material or use it for any profit-making activity or commercial gain

- You may freely distribute the URL identifying the publication in the public portal 


\title{
Title
}

In Vitro Evaluation of Skin Adhesives during Perspiration

\section{Authors}

Johannes Eiler ${ }^{\mathrm{a}, \mathrm{b}}$ (joeil@kemi.dtu.dk)

Daniel Hansen ${ }^{\mathrm{a}, \mathrm{b}}$ (danha@kemi.dtu.dk)

Bahar Bingöl ${ }^{\mathrm{b}}$ (dkbbi@ coloplast.com)

Kristoffer Hansen ${ }^{\mathrm{b}}$ (dkkrh@ coloplast.com)

Jason Heikenfeld ${ }^{\mathrm{c}}$ (heikenjc@ucmail.uc.edu)

Esben Thormann ${ }^{\mathrm{a}}$ (esth@kemi.dtu.dk, corresponding author)

${ }^{a}$ Department of Chemistry, Technical University of Denmark, 2800 Kgs. Lynbgy, Denmark

${ }^{\mathrm{b}}$ Coloplast A/S, 3050 Humlebæk, Denmark

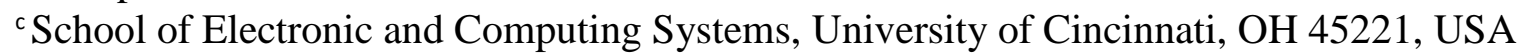

\begin{abstract}
To bridge the gap between current in vitro and in vivo testing, we present the use of a perspiration simulator to evaluate the performance of skin adhesives during sweating. The perspiration simulator mimics human skin in key aspects such as roughness, water contact angle, sweat pore size, sweat pore density, and can be operated at different perspiration rates. In contrast to in vivo testing, a well-defined experimental setup with minimal variation is therefore successfully achieved. To demonstrate the capabilities of the reported perspiration simulator, two model adhesives with different water absorption capabilities are assessed. The peel forces as a function of time are thereby measured during perspiration of a $0.154 \mathrm{M} \mathrm{NaCl}$ solution. The peel force decreases immediately when the perspiration rate exceeds the water uptake as determined by an immersion test. However, when the water absorption capabilities are sufficiently high, a delay in the decrease in peel force is observed. Through the use of a fluorescent dye, we can further correlate the loss of adhesion with a spreading of liquid at the skin-adhesive interface.
\end{abstract}

\section{Keywords}

Artificial Skin, Perspiration, C. Peel, D. Adhesion, D. Interfaces 


\section{Graphical Abstract}

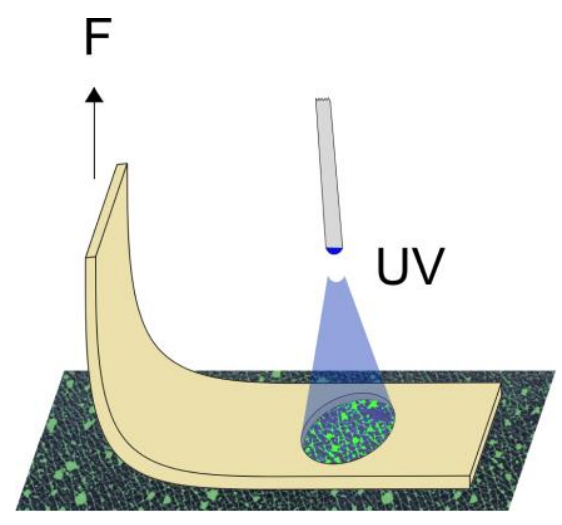

\section{Introduction}

Pressure-sensitive adhesives (PSAs) are polymeric materials that bond to surfaces solely due to van der Waals interactions generated by a mild pressure. Since they do not rely on any chemical reaction, irradiation, or heat and due to the possibility to design strong and yet removable adhesives they have widespread applications. In this work, we focus on medical adhesives, which are worn directly on the skin to aid wound healing, introduce pharmaceutically active ingredients, or attach devices[1-9].

Maintaining adhesion during prolonged wear is thereby crucial to ensure patient safety and therapeutical efficacy. However, some studies have shown that the peel strength of skin adhesives decreases upon perspiration. This loss of adhesion was speculated to be caused by moisture at the interface, where the presence of free water could perturb the skin-adhesive interactions or cause a change in skin surface energy through hydration[10-12]. Regardless of the failure mechanism, it has become widely accepted that the removal of moisture from the skin-adhesive interface is vital for retaining adhesion during perspiration[10-15]. 
To allow moisture transport away from the skin, hydrocolloids are therefore often added to the polymer matrix of the PSA, resulting in better skin health[16-18] and stronger adhesion during perspiration[19,20]. The performance of the adhesive formulations is then typically evaluated through clinical trials. However, in vivo studies are expensive, time-consuming, and suffer from large variabilities. This is problematic when the variations in adhesion to human skin outweigh the effects of formulation adjustments. Parameters like skin roughness, surface energy, sweat rate, as well as sweat composition not only differ between individuals but also depend on the environmental conditions and it is thus difficult to evaluate the effect of perspiration on the adhesive performance[11,21-28]. This might be the reason Roy et al. failed to reach statistical significance when comparing adhesion before and after exercise, even though the individual test samples showed up to a $65 \%$ decrease in peel force[29].

Ex vivo, the performance of medical PSAs is currently assessed in a multi-step approach, where the ability to absorb moisture and the adhesive strength are evaluated separately. The moisture handling capabilities are often determined gravimetrically via immersion in saline solution[30]. The entire surface of the adhesive is thereby exposed to the aqueous environment and the weight increase is monitored periodically. This does not directly translate into a wear situation because sweat glands only make up approx. $0.5 \%$ of the abdominal skin area (with an average of 100 sweat glands $/ \mathrm{cm}^{-2}$ and a diameter of $50-80$ $\mu \mathrm{m})[27]$. Additionally, the distance between sweat glands equates to approx. $1 \mathrm{~mm}$ and therefore a large portion of the PSA initially remains dry during perspiration on human skin (see illustration in Figure 1). Moreover, sweat is supplied in finite volumes and rates on human skin, whereas an excess of liquid is constantly present during an immersion test. Consequently, an immersion test grossly overestimates the moisture handling capabilities of PSAs on human skin. 


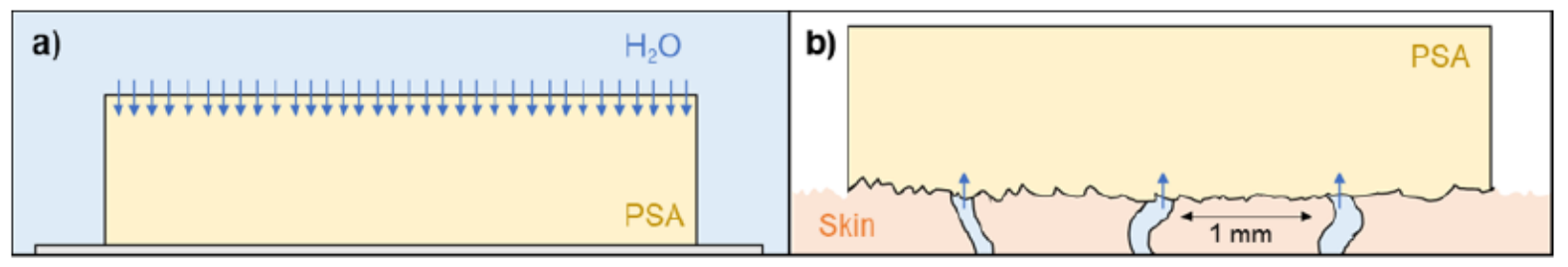

Figure 1. Schematic representation of the adhesive exposure to liquid during a) an industrytypical immersion test and b) the adhesive on the skin, where sweat glands cover approx. $0.5 \%$ of the abdominal skin area.

Adhesion is typically evaluated through peel or tack tests on substrates like steel or glass[31,32]. Repeatable peel force measurements can be achieved, however, these substrates do not mimic the surface energy, topography, or mechanical properties of human skin. Furthermore, measurements are routinely performed under dry conditions, limiting the predictability of adhesion during prolonged wear. Though, some experimental studies of adhesion under wet conditions are reported in literature. As an example, Bowditch discussed the effects on adhesion when a bonded structure was immersed in water or exposed to a humid environment[33]. Moisture thereby reached the interface via diffusion through the adhesives and caused a reduction in bond strength. In a different approach, Karnal et al. first immersed a PSA in water before contact with a tack probe was established[34]. A reduction in adhesive strength was also observed in this case as compared to dry conditions. Even though these studies give insights into the complex interactions between a PSA, the substrate, and water, none of these experiments mimic perspiration below an adhesive, where a PSA is applied under dry conditions and sweat is subsequently transported to the interface in a liquid state.

It becomes evident that a repeatable test protocol is needed to understand adhesion phenomena during perspiration and to develop new adhesives. This study introduces a perspiration simulator that is able to evaluate the performance of skin adhesives during 
perspiration. With the simulator, it is possible to replicate typical values of skin roughness, sweat gland size, sweat gland density, sweat composition, as well as sweat rates. In contrast to human skin, where these parameters change during perspiration, the experimental setup remains constant with the perspiration simulator. This reproducibility is a distinct advantage when compared to in vivo studies and allows for precise control of the test conditions, enabling an understanding of the effects of changes in material compositions on the adhesive performance. Moreover, with the perspiration simulator it is also possible to adjust the liquid composition as desired. This permits us to introduce a fluorescent dye in order to follow the movement of the liquid at the interface between the PSA and the substrate.

\section{Materials and Methods}

\subsection{Perspiration Simulator}

In order to solely probe the effect of perspiration, the perspiration simulator is a simplification of the conditions on human skin. A rigid substrate is chosen for the simulator in order to minimize energy dissipation in the substrate and keep a constant angle during peel. This is in contrast to human skin, where deformations in the skin during peel can greatly affect the measured forces. Additionally, unlike human skin, the selected substrate is not able to hydrate upon exposure to water. Though this does not perfectly represent the conditions during sweating on human skin, the surface and mechanical properties are kept constant. In this study, we apply a modified version of the perspiration simulator previously described by Hou et al. which was later used to develop sweat sensing technology[35-37]. Briefly, the simulator consisted of a sophisticated artificial skin membrane which was glued to an acrylic holder, enabling a homogeneous flow of liquid even at very low rates. Also in this study, in order to create the surface pattern on the artificial skin, a replica of a human forearm was created with a two-component silicone resin (Repliflo, CuDerm, USA). The pattern was then imprinted 
onto a $50 \mu \mathrm{m}$ thick negative photoresist film (MX5050, Dupont, USA) at $95{ }^{\circ} \mathrm{C}$ and approx. $100 \mathrm{kPa}$. The film was cured through exposure to UV light with a wavelength of $365 \mathrm{~nm}$ for $30 \mathrm{~s}$ at $4 \mathrm{~mW} \mathrm{~cm}^{-2}$. Once the skin topography was established, the polymer film was cured under UV exposure. A second layer of the UV-curable polymer film was attached to the back side of the patterned, cured film to give mechanical stability for adhesion testing. The sweat pores with a density of $100 \mathrm{~cm}^{-2}$ were then created with a VLS3.50 $\mathrm{CO}_{2}$ laser (Univerval Laser Systems, USA) before a track-etched membrane (hydrophilic Polycarbonate with pore diameter: $5 \mu \mathrm{m}$, pore density: $4 \mathrm{e} 5 \mathrm{~cm}^{-2}$, thickness: $21 \mu \mathrm{m}$, it4ip, Belgium) was adhered to the artificial skin (see Figure 2). The topography of the artificial skin was evaluated using a Dektak 3030 mechanical profilometer (Bruker, USA). The static water contact angle of the smooth artificial skin was assessed using a ThetaLite 100 optical tensiometer (Biolin Scientific, Sweden). A water droplet with a volume of approx. $10 \mu \mathrm{L}$ was placed on the surface for $30 \mathrm{~s}$ before the contact angle was monitored over a period of $10 \mathrm{~s}$.

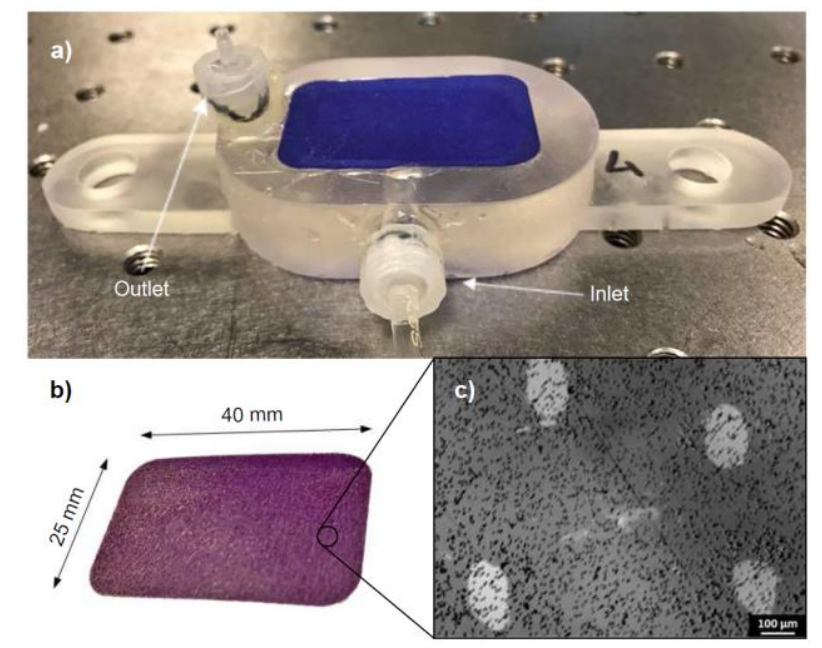

Figure 2. a) The perspiration simulator with an inlet and outlet valve in the reservoir. b) The artificial skin membrane. c) Microscopy image of the artificial skin: The dark spots are the holes of the track-etched membrane with an average diameter of $5 \mu \mathrm{m}$, whereas the large bright spots are the holes in the top membrane.

A larger area with a rectangular geometry was necessary to evaluate adhesion through peel experiments. Therefore, to further optimize the simulator for adhesive testing, a water reservoir was designed to fit a piece of artificial skin with a length of $40 \mathrm{~mm}$ and a width of 
$25 \mathrm{~mm}$. Additionally, to allow for dwelling of the adhesives under dry conditions, it was necessary to fill the reservoir with liquid after the application of the PSA. Hence, an outlet valve was included which could be opened during filling to avoid bubble formation in the reservoir (see Figure 2).

\subsection{Adhesives}

Two rubber-based composite systems were investigated in this study. In both cases, a mixture of polyisobutene (PIB, BASF, Germany) and styrene-isoprene-styrene (SIS, Kraton, USA) was used as the polymer matrix. PIB is typically used in PSAs to provide adhesion and SIS is added to improve the mechanical properties. With a SIS content of the polymer matrix of 40 wt.\%, the PSAs in this study were designed to be mechanically stiff, in order to avoid cohesive failure during peel as well as cold-flow after application. To achieve different water absorption profiles, 19.3 vol.\% of either sodium polyacrylic acid (PAA, Stewart

Superabsorbent, USA) or cetyl hydroxyethyl cellulose particles (CHEC, Ashland, USA) were mixed into the polymer matrix. A Brabender Plastograph (Brabender, Germany) was used to mix the particles into the matrix at $30 \mathrm{rpm}$ at $90{ }^{\circ} \mathrm{C}$ for $45 \mathrm{~min}$ under vacuum. The samples were then pressed to a thickness of $1 \mathrm{~mm}$ in between two release liners (siliconized paper). A hydraulic press (Stenhøj, Denmark) at $90{ }^{\circ} \mathrm{C}$ was used at a load of $10 \mathrm{t}$ with a holding time of $30 \mathrm{~s}$.

The rheological properties of the PSAs were evaluated with a Mars 40 rheometer with a parallel plate geometry (Haake, Germany). The measurements were performed in duplicate and an average of the measured values is reported. Amplitude sweeps at a frequency of $1 \mathrm{~Hz}$ were performed to determine the linear viscoelastic region. Subsequently, frequency sweeps in the linear viscoelastic region were run from $100 \mathrm{~Hz}$ to $0.01 \mathrm{~Hz}$ to characterize the PSAs. The dry peel force of the PSAs on the artificial skin was assessed with a force gauge (Dillon, 
USA and Instron, USA) at a peel rate of $3.5 \mathrm{~mm} / \mathrm{s}$ with a constant peel angle of $90^{\circ}$. To apply the adhesives to the artificial skin in a reproducible manner, weights were placed on a soft silicone pad with an area of $40 \mathrm{~mm}$ by $25 \mathrm{~mm}$ to evenly distribute the load. To test the water absorption capabilities, the samples were immersed into $0.154 \mathrm{M} \mathrm{NaCl}$ solution and their water uptake was assessed gravimetrically (6 replicates were tested simultaneously). The PSAs were removed periodically from the saline solution, weighed and re-immersed.

\subsection{Perspiration Experiments}

The PSAs were applied to the artificial skin using soft silicone pads under well-defined pressures for a constant time interval of $1 \mathrm{~min}(7 \mathrm{kPa}$ for the PAA adhesive and $14 \mathrm{kPa}$ for the CHEC adhesive). The adhesives were applied with different pressures to yield the same initial peel force (approx. $0.7 \mathrm{~N}$ ) which allowed for a direct comparison of the PSAs with respect to their water absorption capabilities rather than the effect of the different rheological properties. After application, the reservoir was filled with liquid, the outlet valve of the reservoir was closed, and the perspiration experiment was started. To determine the effect of perspiration on adhesion, a saline solution of $0.154 \mathrm{M} \mathrm{NaCl}$ was pumped with a syringe pump (kd Scientific, USA and KF Technology, Italy) to mimic human sweat. Two distinct rates of $0.5 \mu \mathrm{L} / \mathrm{cm}^{2} / \mathrm{min}$ and $2.0 \mu \mathrm{L} / \mathrm{cm}^{2} / \mathrm{min}$ were applied, which corresponded to medium and high perspiration rates in the abdominal area, respectively[25]. After predetermined exposure times, the pump was stopped and the PSAs were peeled off the artificial skin with a force gauge (Dillon, USA and Instron, USA) and discarded thereafter.

In a separate experiment, the saline solution was substituted with an aqueous solution containing $0.5 \mathrm{mM}$ fluorescent dye (disodium fluorescein from Exciton, USA) which was pumped at a medium perspiration rate of $0.5 \mu \mathrm{L} / \mathrm{cm}^{2} / \mathrm{min}$. Images were taken periodically during the experiment under UV irradiation to monitor the movement of the liquid. The 
experiments were conducted to monitor the skin-adhesive interface for $60 \mathrm{~min}$ (CHEC adhesive) and 120 min (PAA adhesive), respectively, without any peel force measurements.

\section{Results and Discussion}

\subsection{Perspiration Simulator Characterization}

To illustrate the similarities between the perspiration simulator and human skin, several different characterizations were undertaken. As the artificial skin was created by imprinting a mold of human skin into a polymer membrane, a remarkable topographical resemblance was achieved (see Figure 3). The skin structure with all grooves and crevices was replicated and typical values for the arithmetic mean roughness of $12.1 \pm 1.3 \mu \mathrm{m}$ were achieved. In comparison, arithmetic mean skin roughness values of the volar forearm between $12-29 \mu \mathrm{m}$ are reported in literature[21-23]. Besides age and gender, skin roughness also greatly depends on skin hydration. This implies that skin roughness can change during perspiration in human skin and potentially affect the contact area between the skin and the PSA[38,39]. As the artificial skin in our simulator consists of a UV-cured polymer film, skin hydration is avoided and a constant roughness during perspiration can be assumed. 

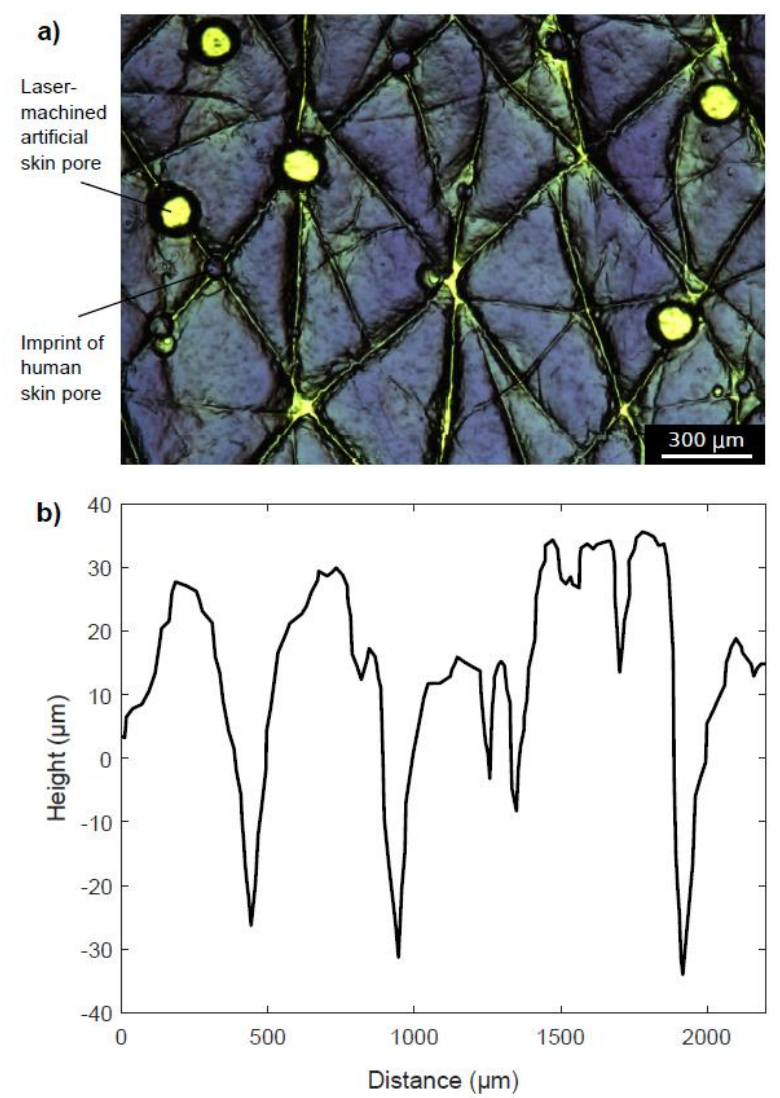

Figure 3. Topology of the artificial skin: a) Microscopy image of the surface of the artificial skin with laser-machined sweat pores (bright circles) as well as original sweat pores from human skin (blue circles). b) Roughness profile as determined with a mechanical profilometer.

The images also show the laser-machined pores in the artificial skin with an average diameter of approx. $86.8 \pm 17.5 \mu \mathrm{m}$. In comparison, the diameter of human skin pores could be estimated to approx. $58.8 \pm 20.0 \mu \mathrm{m}$ from the imprint on the artificial skin. The artificial sweat pores were therefore confirmed to have similar sizes to human skin pores.

The static water contact angle was measured on the UV-cured artificial skin without any topographical imprint and was found to be $69.2 \pm 3.6^{\circ}$. On human skin, the water contact angle shows large variations and greatly depends on the pre-treatment. Ginn et al. showed that the contact angle can vary between $58^{\circ}$ without any treatment and $139^{\circ}$ after a solventwash[24]. Additionally, they found that the contact angle decreases with increasing temperature as well as increasing relative humidity. During perspiration, human skin can 
hydrate which induces a change in skin surface energy. Contrarily, the surface energy of the artificial skin remains constant due to its lack of hydration.

Two pump rates of 0.5 and $2.0 \mu \mathrm{L} / \mathrm{cm}^{2} / \mathrm{min}$ were applied with a syringe pump and the corresponding perspiration rates from the perspiration simulator were measured gravimetrically. A good agreement between the pump and perspiration rate with a steady flow of liquid was observed. In vivo, a large variability in perspiration rates is seen depending on the individual, the amount of exercise, the environmental conditions, and the body part $[26,27,40]$. Furthermore, not only the perspiration rates are different but also the electrolyte concentrations in the sweat[28]. Constant perspiration rates with a constant electrolyte concentration can be realized with our perspiration simulator in order to exclude some of the variations from in vivo testing.

\subsection{Adhesive Characterization}

The rheological properties of the adhesives were evaluated in frequency sweep experiments. The addition of particles to the matrix yielded an increase in storage and loss moduli, G' and G', as compared to the polymer matrix (see Figure 4). A greater increase was observed for the addition of CHEC particles, possibly owing to its elongated particle morphology. The increased moduli of the CHEC adhesive resulted in a higher resistance to flow, which manifested itself in the peel force. When the adhesives were applied to the artificial skin with the same pressure $(14 \mathrm{kPa})$, a lower initial peel force was observed for the CHEC adhesive ( $0.7 \mathrm{~N}$ and $1.1 \mathrm{~N}$ respectively) as the flow into the grooves was restricted. Subsequently, the PAA adhesive was applied with a smaller pressure of $7 \mathrm{kPa}$ in order to yield the same initial peel force of $0.7 \mathrm{~N}$. 


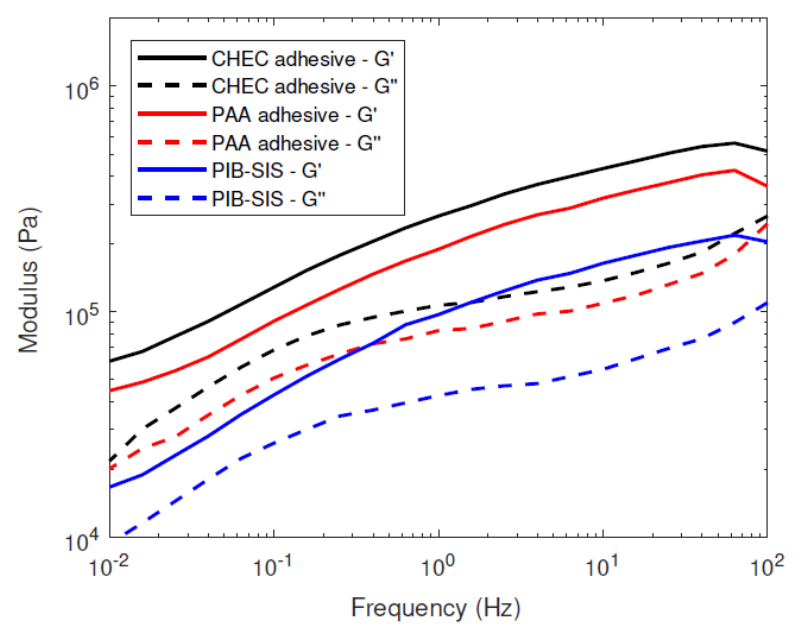

Figure 4. Storage and loss moduli of the adhesives as a function of frequency. An increase in stiffness was observed for the addition of particles.

A critical modulus, $\mathrm{G}_{\mathrm{c}}$, above which the flow of the PSA is restricted under no load, was estimated using the Johnson-Kendall-Roberts theory[41,42]:

$$
G_{c}=\frac{\pi W\left(1-v^{2}\right)}{2} \sqrt{\frac{3 R}{d^{3}}}
$$

With a typical work of adhesion, $\mathrm{W}=0.04 \mathrm{~N} / \mathrm{m}[43]$, the Poisson ratio of rubber, $v=0.5$ [44], a skin asperity radius, $\mathrm{R}=10 \mu \mathrm{m}$, and a skin groove depth, $\mathrm{d}=12 \mu \mathrm{m}$, the critical modulus becomes $\mathrm{G}_{\mathrm{c}}=6.2 \mathrm{kPa}$. The moduli of the CHEC as well as the PAA adhesive exceed this value at all tested frequencies. No further flow after the application is therefore expected for the PSAs and the peel force is assumed to remain constant under dry conditions.

Prior to evaluation on the perspiration simulator, the adhesives were also tested in a standard immersion experiment, where the samples were fully submersed in a $0.154 \mathrm{M} \mathrm{NaCl}$ solution and their weight uptake was monitored gravimetrically. While the PAA adhesive showed a higher water absorption than the CHEC adhesive, both PSAs exhibited a monotonic weight increase with time. A high initial uptake was observed for the PAA adhesive, possibly caused by particles at the surface whose swelling was not restricted by the matrix. The results are depicted in Figure 5 along with the intended perspiration rates on the perspiration simulator. 


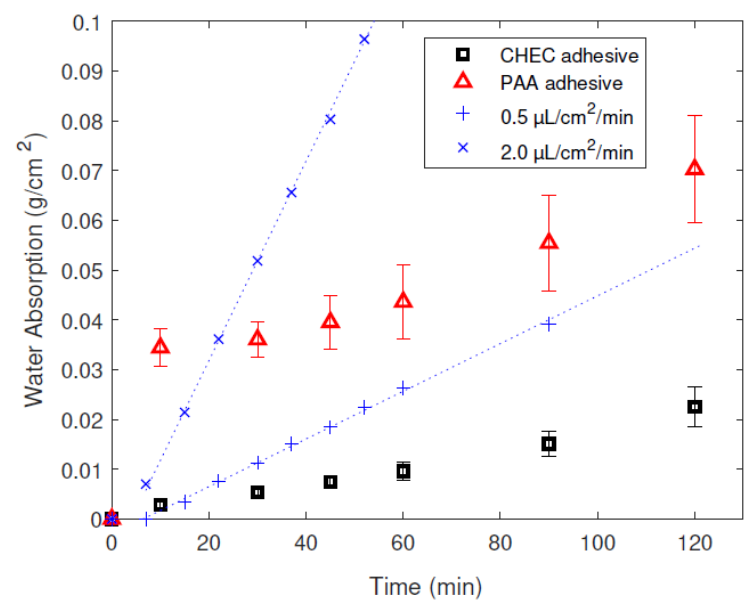

Figure 5. Immersion test data for the two adhesives during an immersion test in $0.154 \mathrm{M} \mathrm{NaCl}$ solution. The applied pump rates on the perspiration simulator are depicted as dashed lines.

If the applied perspiration rate exceeds the water uptake capabilities of the PSA, a pressure build-up is expected as the adhesive will effectively block the pores. If the pressure then exceeds the adhesive strength, a flooding of the interface is expected to occur, resulting in a reduction of adhesion. Due to the low peel forces of $0.7 \mathrm{~N}$ in our study, pressure buildup is minimized and flooding will occur readily. On the other hand, if the water uptake capabilities of the PSA exceed the perspiration rate, parts of the interface will remain dry and adhesion will be retained. To test the hypothesis, a medium perspiration rate of $0.5 \mu \mathrm{L} / \mathrm{cm}^{2} / \mathrm{min}$ is chosen which exceeds the uptake capabilities of the CHEC adhesive but not the PAA adhesive. A decrease in peel force over time is therefore expected for the CHEC adhesive, whereas the PAA adhesive is thought to remove the supplied liquid adequately and therefore maintain adhesion during perspiration. Finally, a high rate of $2.0 \mu \mathrm{L} / \mathrm{cm}^{2} / \mathrm{min}$ is applied at which both PSAs are expected to lose adhesion readily.

\subsection{Perspiration Experiments}

To visualize the flow of sweat at the skin-adhesive interface, a solution containing a fluorescent dye was pumped with the perspiration simulator at a rate of $0.5 \mu \mathrm{L} / \mathrm{cm}^{2} / \mathrm{min}$. While the artificial skin was covered by the PSA, it was possible to trace the fluorescent 
liquid through the adhesive under UV irradiation. This way, different spreading behaviors of the liquid could be identified depending on the adhesive that was used. The portion of the dry interface during perspiration was calculated using the image analysis software Fiji[45]. In line with the expectations, the dry contact area between the substrate and the CHEC adhesive decayed rapidly within $60 \mathrm{~min}$ (see Figure 6). The perspiration rate exceeded the uptake rate and caused the liquid to spread uncontrollably until the entire interface was flooded. In contrast, a spreading of the liquid was delayed below the PAA adhesive. Within the first 60 min, the liquid was confined to multiple separate areas across the interface. These areas likely corresponded to the sweat pores, where the liquid was absorbed directly into the PSA.

Eventually, the liquid also spread beneath the confined areas and flooded the entire interface even though the water uptake capacity exceeded the amount of perspiration. This demonstrates that the immersion test indeed overestimates the water-handling abilities of the PSA. 


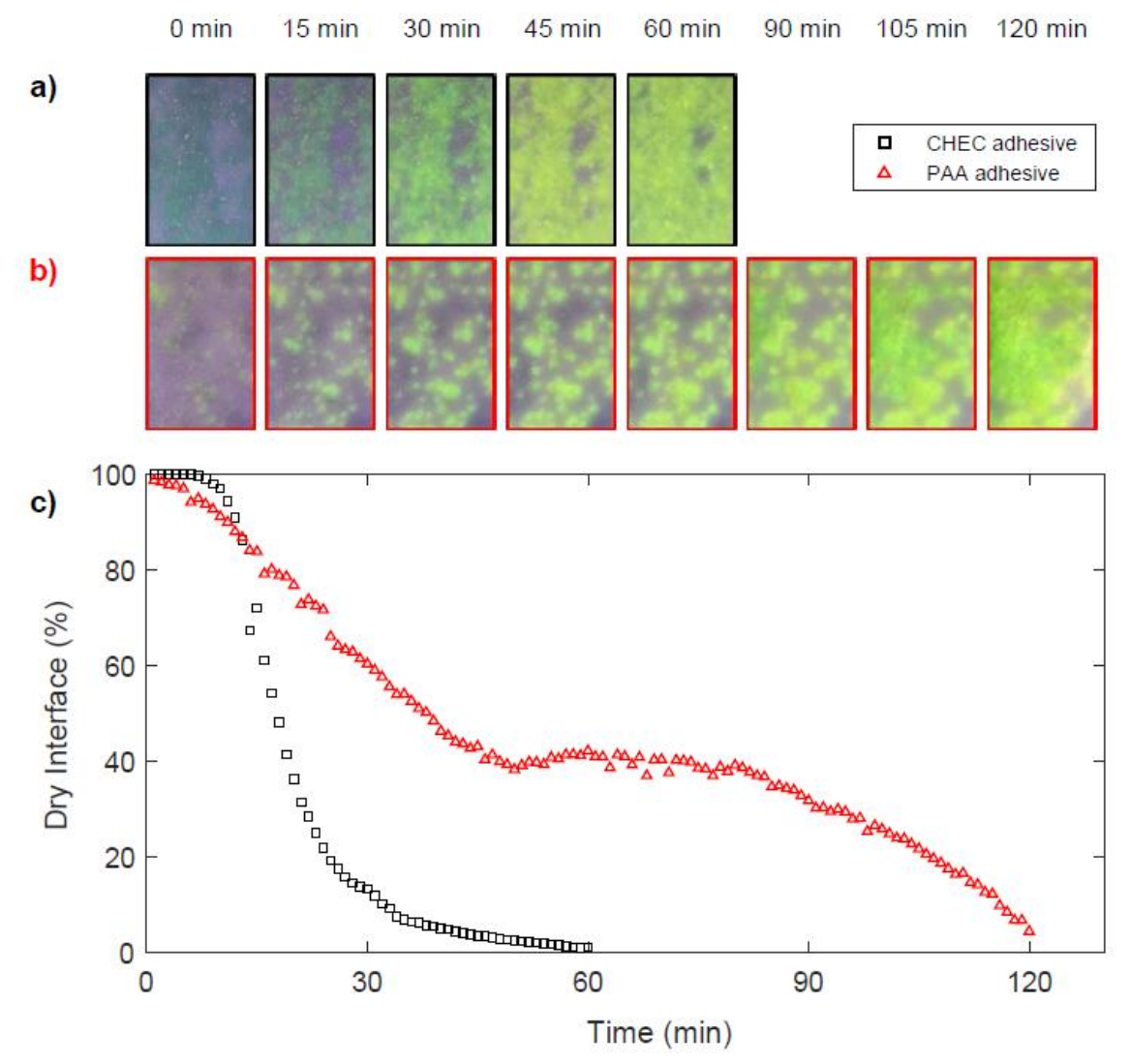

Figure 6. Images of the adhesives on the perspiration simulator during UV exposure while pumping a fluorescent liquid. a) Below the CHEC adhesive, a rapid spreading of the liquid was observed. b) Below the PAA adhesive, the liquid was confined to the areas of the sweat glands during the first $60 \mathrm{~min}$, a spreading was observed thereafter. c) The dry contact area between the adhesives and the artificial skin was determined from the images.

To determine the effect of perspiration on adhesion, a saline solution of $0.154 \mathrm{M} \mathrm{NaCl}$ was pumped at the same rate of $0.5 \mu \mathrm{L} / \mathrm{cm}^{2} / \mathrm{min}$. At specific time points, the adhesives were peeled off the perspiration simulator and force curves were recorded. After an initial increase in peel force, an average was determined in the steady-state region for each curve. The average peel forces were then evaluated as a function of perspiration time and related to the spreading behavior as determined with the fluorescent liquid. Due to the fact that each data point corresponds to a separate experiment on a rough substrate with a new piece of adhesive, some variation was observed. Nonetheless, an overall trend towards a reduction in adhesion with perspiration time became apparent. The CHEC adhesive showed a monotonic decrease in peel force as a function of perspiration time and a drop from an initial value of $0.7 \mathrm{~N}$ to $0.0 \mathrm{~N}$ 
after approx. 60 min (Figure 7). Contrarily, the PAA adhesive exhibited a plateau region up to $60 \mathrm{~min}$, where the peel force stayed relatively constant. Thereafter, the peel force also started to decrease monotonically. This loss of adhesion occurred simultaneously with a spreading of liquid at the interface as seen with the fluorescent marker and coincided with these findings.

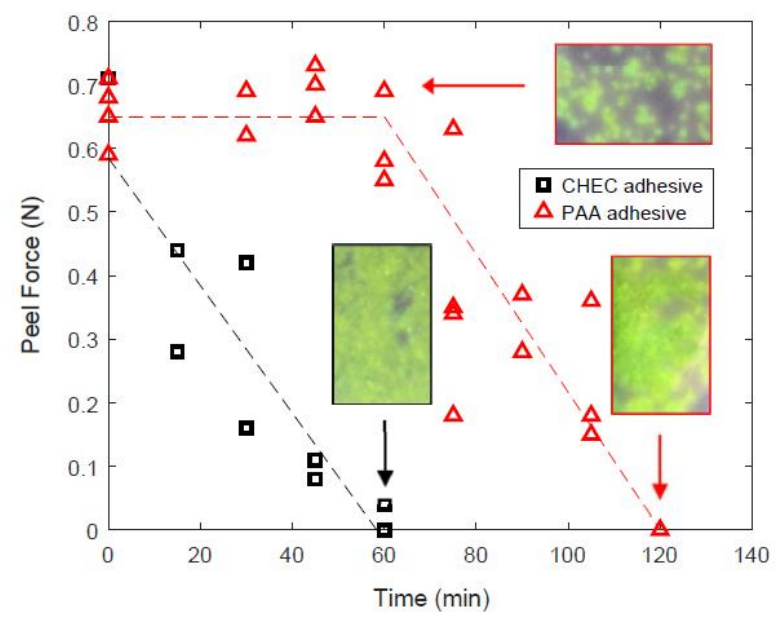

Figure 7. Peel forces at different time points after pumping $0.154 \mathrm{M} \mathrm{NaCl}$ solution at a rate of $0.5 \mu \mathrm{L} / \mathrm{cm}^{2} / \mathrm{min}$. The CHEC adhesive showed a monotonic decrease in peel force from the beginning. A decreasing peel force was first observed at a later time point for the PAA adhesive. The dashed lines represent a guide for the eyes.

At a high perspiration rate of $2.0 \mu \mathrm{L} / \mathrm{cm}^{2} / \mathrm{min}$, however, the absorption capabilities of both adhesives were exceeded. At such high perspiration rates, the peel forces of the CHEC adhesive and the PAA adhesive decreased similarly as a function of perspiration time (see Figure 8). Neither of the adhesives was able to retain adhesion during this condition and both adhesives appeared to behave equally poor. Therefore, in order to distinguish the performance of different PSA formulations during perspiration, the test conditions have to be controlled carefully. 


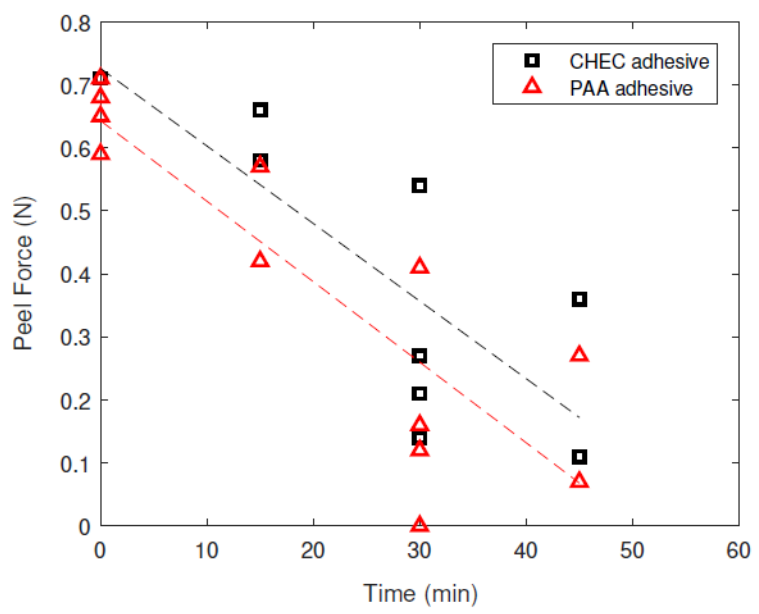

Figure 8. Peel forces at different time points after pumping $0.154 \mathrm{M} \mathrm{NaCl}$ solution. At a pump rate of $2.0 \mu \mathrm{L} / \mathrm{cm}^{2} / \mathrm{min}$ the peel forces of the CHEC adhesive and the PAA adhesive decreased in a similar fashion and the samples could not be distinguished. The dashed lines represent a guide for the eyes.

\section{Conclusions}

The perspiration simulator presents a new in vitro method to evaluate the performance of medical adhesives during sweating. In contrast to current screening methods, where the adhesion and moisture handling capabilities of PSAs are evaluated separately, the perspiration simulator allows for a simultaneous assessment of these parameters. An adhesive is thereby applied to an artificial skin under dry conditions before a liquid is pumped directly to the skinadhesive interface. The artificial skin mimics key characteristics of human skin including roughness, water contact angle, sweat pore size and sweat pore density. In contrast to human skin, however, these parameters remain constant during perspiration on our simulator and therefore present a well-defined experimental setup. Additionally, the composition of the liquid as well as the perspiration rate can be precisely controlled and adjusted to the research needs. This makes the perspiration simulator a powerful tool to test new adhesive formulations and presents an alternative for current in vitro and in vivo testing of medical adhesives. 
Two adhesives with different moisture uptake abilities were designed for evaluation on the perspiration simulator. We hypothesized that adhesion could only be maintained if the absorption capabilities of the PSA exceeded the pump rate. Based on the absorption capabilities from the immersion test, perspiration rates were chosen to distinguish between the adhesives. With the use of a fluorescent dye, we could show that pump rates which exceeded the moisture uptake abilities of the PSAs led to a spreading of the liquid at the interface. This spreading was then associated with an immediate reduction in peel strength. On the other hand, when the pump rate was lower than the absorption rate, the liquid was prohibited from spreading and the loss of adhesion was delayed. Even though the immersion test overestimated the water handling capabilities of the PSAs on skin, it was able to predict whether immediate or delayed failure occurred.

\section{Acknowledgements}

We would like to thank the Innovation Fund Denmark for financial support through the Grand Solutions Project \#6151-00007B. 


\section{References}

[1] Kannon GA, Garrett AB. Moist wound healing under occlusive dressing: A Clinical Review. Dermatologic Surg 1995;21:583-90.

[2] Thomas S. Hydrocolloid dressings in the management of acute wounds: A review of the literature. Int Wound J 2008;5:602-13. doi:10.1111/j.1742-481X.2008.00541.x.

[3] Venkatraman S, Gale R. Skin adhesives and skin adhesion. Biomaterials 1998;19:1119-36.

[4] Wokovich AM, Prodduturi S, Doub WH, Hussain AS, Buhse LF. Transdermal drug delivery system (TDDS) adhesion as a critical safety, efficacy and quality attribute. Eur J Pharm Biopharm 2006;64:1-8. doi:10.1016/j.ejpb.2006.03.009.

[5] Felix J, Bishay JM, Bardy GH. Extended wear electrocardiography patch using interlaced wire electrodes. US 9,717,432 B2, 2017.

[6] Hung M-W, Wu C-L, Chiu Y-Y. Long term physiological signal sensing patch. US 2017/0164860 A1, 2017.

[7] Hwang I, Kim HN, Seong M, Lee S-H, Kang M, Yi H, et al. Multifunctional Smart Skin Adhesive Patches for Advanced Health Care. Adv Healthc Mater 2018;7:1800275. doi:10.1002/adhm.201800275.

[8] Tighe BJ, Mann A. Adhesives and interfacial phenomena in wound healing. In: Farrar D, editor. Adv. Wound Repair Ther., Elsevier; 2011, p. 247-83. doi:10.1533/9780857093301.2.247.

[9] Lipani L, Dupont BGR, Doungmene F, Marken F, Tyrrell RM, Guy RH, et al. Noninvasive, transdermal, path-selective and specific glucose monitoring via a graphenebased platform. Nat Nanotechnol 2018;13:504-11. doi:10.1038/s41565-018-0112-4.

[10] Spencer TS, Smith SE, Conjeevaram S. Adhesive interactions between polymers and skin in transdermal delivery systems. Polym Mater Sci Eng Proc Acs Div Polym Mater Sci Eng 1990;63:337. 
[11] Kenney JF, Haddock TH, Sun RL, Parreira HC. Medical-grade acrylic adhesives for skin contact. J Appl Polym Sci 1992;45:355-61. doi:10.1002/app.1992.070450218.

[12] Renvoise J, Burlot D, Marin G, Derail C. Peeling of PSAs on Viscoelastic Substrates: A Failure Criterion. J Adhes 2007;83:403-16. doi:10.1080/00218460701282554.

[13] Horstmann M, Müller W, Asmussen B. Principles of Skin Adhesion and Methods for Measuring Adhesion of Transdermal Systems. In: Mathiowitz E, Chickering Ill DE, Lehr C-M, editors. Bioadhesive Drug Deliv. Syst. - Fundam. Nov. Approaches Dev., 1999, p. 175-96.

[14] Renvoise J, Burlot D, Marin G, Derail C. Adherence performances of pressure sensitive adhesives on a model viscoelastic synthetic film: A tool for the understanding of adhesion on the human skin. Int J Pharm 2009;368:83-8. doi:10.1016/j.ijpharm.2008.09.056.

[15] Cunningham DD, Lowery MG. Moisture Vapor Transport Channels for the Improved Attachment of a Medical Device to the Human Body. Biomed Microdevices 2004;6:149-54. doi:10.1023/B:BMMD.0000031752.63215.61.

[16] Matsumura H, Oka K, Umekage K, Akita H, Kawai J, Kitazawa Y, et al. Effect of occlusion on skin. J Dermatolog Treat 1997;8:139-42. doi:10.3109/09546639709160288.

[17] Zhai H, Maibach HI. Occlusion vs. skin barrier function. Ski Res Technol 2002;8:1-6. doi:10.1046/j.0909-752x.2001.10311.x.

[18] Gray M, Black JM, Baharestani MM, Bliss DZ, Colwell JC, Goldberg M, et al. Moisture-associated skin damage: Overview and pathophysiology. J Wound, Ostomy Cont Nurs 2011;38:233-41. doi:10.1097/WON.0b013e318215f798.

[19] Ferrari F, Bertoni M, Bonferoni MC, Rossi S, Caramella C, Waring MJ. Comparative evaluation of hydrocolloid dressings by means of water uptake and swelling force measurements: I. Int J Pharm 1994;112:29-36. doi:10.1016/0378-5173(94)00301-K. 
[20] Lipman R. Hydrocolloid PSAs: New Formulation Strategies. Med Device Diagnostic Ind Mag 1999:134.

[21] Lagarde JM, Rouvrais C, Black D. Topography and anisotropy of the skin surface with ageing. Ski Res Technol 2005;11:110-9. doi:10.1111/j.1600-0846.2005.00096.x.

[22] Li L, Mac-Mary S, Marsaut D, Sainthillier JM, Nouveau S, Gharbi T, et al. Age-related changes in skin topography and microcirculation. Arch Dermatol Res 2006;297:412-6. doi:10.1007/s00403-005-0628-y.

[23] Egawa M, Oguri M, Kuwahara T, Takahashi M. Effect of exposure of human skin to a dry environment. Ski Res Technol 2002;8:212-8. doi:10.1034/j.16000846.2002.00351.x.

[24] Ginn ME, Noyes CM, Jungermann E. The contact angle of water on viable human skin. J Colloid Interface Sci 1968;26:146-51. doi:10.1016/0021-9797(68)90306-8.

[25] Sato K, Sato F. Individual variations in structure and function of human eccrine sweat gland. Am J Physiol Integr Comp Physiol 1983;245:R203-8.

doi:10.1152/ajpregu.1983.245.2.R203.

[26] Henkin SD, Sehl PL, Meyer F. Sweat Rate and Electrolyte Concentration in Swimmers, Runners, and Nonathletes. Int J Sports Physiol Perform 2010;5:359-66. doi:10.1123/ijspp.5.3.359.

[27] Taylor NA, Machado-Moreira CA. Regional variations in transepidermal water loss, eccrine sweat gland density, sweat secretion rates and electrolyte composition in resting and exercising humans. Extrem Physiol Med 2013;2:4. doi:10.1186/2046-7648$2-4$.

[28] Lara B, Gallo-Salazar C, Puente C, Areces F, Salinero JJ, Del Coso J. Interindividual variability in sweat electrolyte concentration in marathoners. J Int Soc Sports Nutr 2016;13:1-8. doi:10.1186/s12970-016-0141-z.

[29] Roy SH, De Luca G, Cheng MS, Johansson A, Gilmore LD, De Luca CJ. Electro- 
mechanical stability of surface EMG sensors. Med Biol Eng Comput 2007;45:447-57. doi:10.1007/s11517-007-0168-Z.

[30] ASTM D570-98(2018) Standard Test Method for Water Absorption of Plastics, ASTM International, West Conshohocken, PA, 2018 n.d. doi:https://doi.org/10.1520/D057098R18.

[31] Nussinovitch A, Gal A, Padula C, Santi P. Physical Characterization of a New Skin Bioadhesive Film. AAPS PharmSciTech 2008;9:458-63. doi:10.1208/s12249-0089061-9.

[32] Chivers RA. Easy removal of pressure sensitive adhesives for skin applications. Int J Adhes Adhes 2001;21:381-8. doi:10.1016/S0143-7496(01)00015-X.

[33] Bowditch MR. The durability of adhesive joints in the presence of water. Int J Adhes Adhes 1996;16:73-9. doi:10.1016/0143-7496(96)00001-2.

[34] Karnal P, Roberts P, Gryska S, King C, Barrios C, Frechette J. Importance of Substrate Functionality on the Adhesion and Debonding of a Pressure-Sensitive Adhesive under Water. ACS Appl Mater Interfaces 2017;9:42344-53. doi:10.1021/acsami.7b13984.

[35] Hou L, Hagen J, Wang X, Papautsky I, Naik R, Kelley-Loughnane N, et al. Artificial microfluidic skin for in vitro perspiration simulation and testing. Lab Chip 2013;13:1868-75. doi:10.1039/c3lc41231.

[36] Peng R, Sonner Z, Hauke A, Wilder E, Kasting J, Gaillard T, et al. A new oil/membrane approach for integrated sweat sampling and sensing: sample volumes reduced from $\mu \mathrm{L}$ 's to $\mathrm{nL}$ 's and reduction of analyte contamination from skin. Lab Chip 2016;16:4415-23. doi:10.1039/C6LC01013J.

[37] Twine NB, Norton RM, Brothers MC, Hauke A, Gomez EF, Heikenfeld J. Open nanofluidic films with rapid transport and no analyte exchange for ultra-low sample volumes. Lab Chip 2018;18:2816-25. doi:10.1039/C8LC00186C.

[38] Gerhardt L-C, Strassle V, Lenz A, Spencer N., Derler S. Influence of epidermal 
hydration on the friction of human skin against textiles. J R Soc Interface 2008;5:131728. doi:10.1098/rsif.2008.0034.

[39] Adams MJ, Briscoe BJ, Johnson SA. Friction and lubrication of human skin. Tribol Lett 2007;26:239-53. doi:10.1007/s11249-007-9206-0.

[40] Candas V, Brandenberger G, Lutz-Bucher B, Follenius M, Libert JP. Endocrine concomitants of sweating and sweat depression. Eur J Appl Physiol Occup Physiol 1984;52:225-9. doi:10.1007/BF00433397.

[41] Johnson KL, Kendall K, Roberts AD. Surface Energy and the Contact of Elastic Solids. Proc R Soc A Math Phys Eng Sci 1971;324:301-13. doi:10.1098/rspa.1971.0141.

[42] Creton C, Leibler L. How does tack depend on time of contact and contact pressure? J Polym Sci Part B Polym Phys 1996;34:545-54. doi:10.1002/(SICI)10990488(199602)34:3<545::AID-POLB13>3.0.CO;2-I.

[43] Kinning DJ, Schneider HM. Release coatings for pressure sensitive adhesives. In: Dillard DA, Pocius A V., Chaudhury M, editors. Adhes. Sci. Eng., 2002, p. 535-71.

[44] Anderson ML, Mott PH, Roland CM. The Compression of Bonded Rubber Disks. Rubber Chem Technol 2004;77:293-302. doi:10.5254/1.3547824.

[45] Schindelin J, Arganda-Carreras I, Frise E, Kaynig V, Longair M, Pietzsch T, et al. Fiji: an open-source platform for biological-image analysis. Nat Methods 2012;9:676-82. doi:10.1038/nmeth.2019. 